\title{
PENDUGAAN STOK TUNA SIRIP KUNING (Thunnus albacares) MENGGUNAKAN MODEL PRODUKSI SURPLUS (MPS) DI PERAIRAN SAMUDERA HINDIA (STUDI KASUS: SELATAN JAWA TIMUR)
}

\author{
Gussasta Levi Arnenda ${ }^{a}$, Dhimas Amirul Kusuma ${ }^{\text {, }}$, Dimas Galang Fergiawan ${ }^{\text {a,b }}$ \\ ${ }^{a}$ Loka Riset Perikanan Tuna, Jalan Mertasari No 140 Sidakarya, Denpasar, Indonesia \\ ${ }^{\mathrm{b}}$ Fakultas Perikanan dan Ilmu Kelautan, Universitas Brawijaya, Malang, Indonesia \\ *Koresponden penulis : gussastaarnenda@gmail.com
}

\begin{abstract}
Abstrak
Tuna sirip kuning (Thunnus albacares) merupakan salah satu jenis ikan pelagis besar yang dominan ditangkap di Samudera Hindia pada perairan Jawa Timur. Tujuan dari penelitian ini adalah untuk mengestimasikan nilai potensi tangkap maksimum lestari (MSY) dan nilai jumlah tangkapan yang diperbolehkan (JTB), status sumberdaya, jumlah stok ikan tuna sirip kuning pada tahun 2015, dan manajemen pengelolaan sumberdaya perikanan untuk mencapai stok ikan tuna yang optimum di perairan Samudera Hindia pada perairan Jawa Timur. Data sekunder menggunakan data statistik perikanan tangkap Jawa Timur tahun 1990-2015. Berdasarkan hasil analisis didapatkan nilai potensi maksimum tangkap lestari dengan menggunakan model Fox (1970) didapatkan nilai $\mathrm{f}_{\mathrm{MSY}} 1.226 .054$ trip dan nilai $\mathrm{Y}_{\mathrm{MSY}}$ 2.926,59 ton. Kondisi pada saat JTB didapatkan nilai $\mathrm{f}_{\mathrm{JTB}} 578.296$ trip dan $\mathrm{Y}_{\text {JTB }} 2.341,27$ ton. Tingkat pengusahaan sumberdaya ikan tuna dengan acuan nilai $\mathrm{f}_{\mathrm{JTB}}$ didapatkan nilai $107 \%$ dan pemanfaatan biomass dengan acuan nilai JTB yang didapatkan dari non-quilibrium model didapatkan sisa biomass pada tahun $201580 \%$ dari biomass saat JTB, sehingga didapatkan status perikanan tuna over exploited. Pendugaan stok pada tahun 2015 sebesar 11.990,85 ton atau $80 \%$ dari biomass pada saat JTB. Manajemen pengelolaan sumberdaya ikan tuna di Samudra Hindia pada periaran Jawa Timur dengan mensimulasikan upaya penangkapan pada tahun 2016-2025 setara dengan upaya penangkapan tahun 2015 yaitu 486.017 trip dan menghasilkan biomass $12.701,98$ ton.
\end{abstract}

Kata Kunci : pendugaan stok, Samudra Hindia, status perikanan, tuna

\begin{abstract}
Yellow fin Thuna (Thunnus albacares) is one of the dominant large pelagic fish was captured in Indian Ocean. Almost along the south coast of East Java there is a landing of Tuna. The purpose of this research is to find out the estimation of maximum sustainable yield (MSY) and total allowable catch (TAC), the value of exploitation, the status of fisheries, the potential value of sustainable fish reserves in 2015, the alternative management of fish resources to reached the optimum stock in Indian Ocean especially at southern East Java water. The analysis using secondary data of annual report fisheries statistics from 1990-2015. The results of the potential value of sustainable catch (MSY) used Fox model (1970) is YMSY 2,926.59 ton, the value of fMSY 1,226,054 trip. Tuna fisheries on TAC condition obtained value fJTB 578,296 trip and YJTB 2341.27 tons. The fisheries status with reference value of fJTB obtained value of fisheries rate of $107 \%$ and percentages of biomass utilization reference with (TAC) using non-equilibrium model value of utilization obtained biomass 2015 is $80 \%$, then the status of the fisheries was over exploited. Fish stock assessment on 2015 is 11,990.85 tons or 80\% from biomass at TAC. The alternative of fishery resource management in Indian ocean of East Java using simulation value of fishing effort during 2016-2025 period equivalent to effort from 2015 that was48,6017 trip that would be predicted biomass about 12,701.98 tons.
\end{abstract}

Keywords : Indian Ocean, tuna, stock assessment, fisheries status

\section{PENDAHULUAN}

Wilayah Jawa Timur merupakan salah satu provinsi yang menjadi pusat pendaratan ikan tuna, tongkol dan cakalang, utamanya di wilayah pesisir selatan. Umumnya ikan jenis tuna yang didaratkan merupakan pelagis besar, antara lain tuna sirip kuning (Thunnus albacares), tuna albakora 
tangkap yang dominan digunakan adalah pancing ulur, pancing tonda dan rawai hanyut.

Berdasarkan data Statistik Perikanan Tangkap Jawa Timur tahun 1990-2015 hasil tangkapan tuna sirip kuning mengalami fluktuasi hasil tangkapan, dimana terjadi penurunan CpUE dari tahun ke tahun. Hal tersebut disebabkan tingginya upaya penangkapan untuk memenuhi permintaan pasar terhadap kebutuhan ikan tuna sirip kuning, baik di pasar domestik maupun pasar internasional.

Upaya penangkapan ikan tuna sirip kuning yang terus mengalami peningkatan, dikhawatirkan menyebabkan penurunan biomasa sumberdaya ikan. Kondisi tersebut diperlukan suatu pengelolaan terhadap sumberdaya ikan tuna, agar dapat dimanfaatkan secara lestaridan berkelanjutan.

Tujuan dari penelitian ini adalah untuk mengetahui nilai MSY dan JTB dengan menggunakan model equilibrium dan non equilibrium, untuk mengetahui stok perikanan tuna sirip kunign tahun 2015, untuk mengetahui status pemanfaatan biomassa ikan tuna di perairan selatan Jawa Timur, dan untuk mengetahui alternatif pengelolaan sumberdaya ikan tuna sirip kuning di perairan selatan Jawa Timur.

\section{METODE PENELITIAN}

\section{Waktu dan Tempat}

Penelitian ini dilaksanakan pada bulan Januari-April 2017 dengan sampel di Pelabuhan UPT PP Pondok Dadap, Malang, Jawa Timur.

\section{Materi Penelitian}

Pendugaan stok, status perikanan dan cadangan sumberdaya ikan tuna sirip kuning (Thunnus albacares) di perairan Selatan Jawa Timur, menggunakan metode Holistick, dengan menggunakan model equilibrium dengan persamaan Schaefer dan Fox dan untuk model non-equilibrium menggunakan model WalterHilborn. Menduga nilai stok cadangan sumberdaya ikan menggunakan model persamaan Walter-Hilborn [1].

\section{Bahan Penelitian}

Bahan yang digunakan dalam penelitian ini adalah data statistik perikanan tangkap Jawa Timur tahun 1990-2015. Software Microsoft excel dan Microsoft word untuk pengolahan dan penyajian data.

\section{Metode Penelitian}

Metode yang digunakan dalam penelitian ini adalah metode diskriptif kuantitaif karena dalam penelitian melakukan pengolahan data berupa angka serta analisisnya menggunakan statistik, serta menggunakan metode holistik dengan model Surplus produksi model equilibrium dan nonequilibrium (model Walter-hilborn) untuk menduga nilai Maksimum sustainable yield sumberdaya ikan, dan menggunakan model Walter Hilborn untuk mendugan potensi cadangan lestari sumberdaya ikan [1].

\section{Teknik Pengumpulan Data}

\section{a. Data Primer}

Data primer yang digunakan dalam penelitian ini didapatkan dengan metode wawancara dengan narasumber di lokasi pengambilan sampel. Informasi yang dibutuhkan berupa jumlah upaya penangkapan pada saat musim barat dan musim timur yang digunakan dalam penentuan pengelolaan perikanan.

\section{b. Data Sekunder}

Data sekunder dalam penelitian ini didapatkan dari Laporan Statistik Perikanan Provinsi Jawa Timur tahun 1990 - 2015. Laporan tersebut didapatkan dari Dinas Kelautan dan Perikanan Provinsi Jawa Timur, data Data sekunder yang juga digunakan dalam penelitian antara lain artikel ilmiah, buku, jurnal ilmiah, serta dokumen dokumen yang berkaitan dengan pendugaan stok dan status pengusahaan sumberdaya ikan.

\section{Analisis Data}

\section{a. Standarisasi Upaya Penangkapan}

Standarisasi upaya penangkapan bertujuan untuk menyetarakan upaya penangkapan, satu alat tangkap dominan dengan seluruh alat tangkap yang digunakan untuk menangkap ikan tuna sirip kuning (Thunnus albacares) pada seluruh Kabupaten di perairan Selatan Jawa Timur. Alat tangkap yang dominan digunakan dalam penangkapan tuna antara lain pancing tonda, pancing ulur, rawai tetap dan rawai hanyut (ex rawai tuna). Dasar dari standarisasi eksternal ini adalah dengan menggunakan FPI (Fishing Power Index)., perhitungan FPI adalah dengan menggunakan persamaan [2]:

$F P I_{i}=\frac{C p U E_{i}}{C p U E_{S}}$

Keterangan:

$\mathrm{FPI}_{\mathrm{i}} \quad$ : Fising power index alat tangkap

$C p U E_{i}:$ Hasil tangkapan per upaya penangkapan alat tangkap

$C p U E_{S}$ : Hasil tangkapan persatuan upaya alat tangkap standart. 


\section{b. Pendugaan Potensi Tangkap Lestari}

Pendugaan nilai potensi tangkap lestari atau Maximum Sustainable Yield menggunakan model surplus produksi dengan model equilibrium terdiri dari model Schaefer dan Fox, sedangkan model non-equilibrium dengan model Walter-Hilborn [1].

\section{1) Schaefer 1954}

Pendugaan tangkapan maksimum lestari (MSY) diduga dengan persamaan sebagai berikut [3],

$$
\begin{array}{ll}
y_{i} & =(a \times f)+\left(b \times f^{2}\right) \\
y_{i} & =a+2 b f \\
-a & =2 \times b f \\
f_{m S y} & =a / 2 b \\
y_{M S Y} & =a \times f_{M S Y}+b \times f_{M S Y}^{2} \\
y_{M S Y} & =\left(a^{x}\left(\frac{-a}{2^{\mathrm{x}} b}\right)+\mathrm{b}^{\mathrm{x}}\left(\frac{-a}{2^{\mathrm{x}} b}\right)^{2}\right. \\
y_{M S Y} & =\frac{a^{2}}{4^{\mathrm{x}} b} \\
y_{J T B} & =\frac{a^{2}}{4 b} x 80 \% \\
f_{J T B} & =\frac{-b \pm \sqrt{b^{2}-4 a c}}{2 a}
\end{array}
$$

Keterangan:

$$
\begin{array}{ll}
y_{M S Y} & : \text { Tangkapan Maksimum Lestari } \\
f_{M S Y} & : \text { Upaya penangkapan saat (MSY) } \\
y_{J T B} & : \text { Tangkapan saat JTB } \\
f_{J T B} & : \text { Jumlah trip alat tangkapan saat JTB } \\
c & : y_{J T B} \\
a & : \text { Intersep } \\
b & : \text { Slope }
\end{array}
$$

\section{2) Fox 1970}

Pendugaan nilai tangkapan maksimum lestari (MSY) dengan model Fox dapat diduga dengan persamaan sebagai berikut [3],

$$
\begin{aligned}
\operatorname{Ln}\left(\frac{Y_{i}}{f_{i}}\right) & =c+d \times f(i) \\
y_{M S Y} & =\left(\frac{1}{d}\right) \times \exp ^{(c-1)} \\
f_{M S Y} & =\frac{1}{d} \\
y_{J T B} & =\left(\frac{1}{d}\right) \times \exp ^{(c-1)} \times 80 \% \\
f_{J T B} & =f \times \exp ^{(c-d \times f)}-Y_{J T B}=0
\end{aligned}
$$

Keterangan:

$y_{M S Y} \quad$ : Tangkapan Maksimum Lestari

$f_{M S Y} \quad$ : Upaya penangkapan saat (MSY)

$y_{J T B} \quad:$ Tangkapan saat JTB

$f_{J T B} \quad$ : Jumlah trip alat tangkapan saat JTB

c : Intersep

d : Slope
Perhitungan $\mathrm{f}_{\text {Jтв }}$ model Fox merupakan simulasi dengan menggunakan Persamaan 11.

\section{3) Walter-Hilborn 1992}

Pendugaan tangkapan maksimum lestari (MSY), didapatkan pertumbuhan pada kondisi biomass lestari, dengan persamaan [1]:

$$
\begin{array}{ll}
y_{M S Y} & =B e \times r-\left(\frac{r}{k}\right) \times B e^{2} \\
C_{B e} & =q \times f \times B e \\
f_{M S Y} & =\frac{C_{B e}}{B e \times q} \\
y_{J T B} & =B e \times r-\left(\frac{r}{k}\right) \times B e^{2} \times 80 \% \\
B_{J T B} & =B \times r-\left(\frac{r}{k}\right) \times B^{2}-y_{J T B}=0 \\
f_{J T B} & =\frac{C_{J T B}}{B_{J T B x q}}
\end{array}
$$

\section{Keterangan :}

$B e \quad$ : Kondisi pada saat biomass lestari

$C_{B e} \quad$ : Hasil tangkapan pada saat Be

$r \quad:$ Koefisien pertumbuhan

$k \quad$ : Carying capacity

$q \quad:$ Catchapability

$B_{J T B} \quad$ : Biomass pada saat JTB

Perhitungan nilai biomass pada saat JTB $\left(\mathrm{B}_{\mathrm{JTB}}\right)$ merupakan simulasi dengan menggunakan Persamaan (14).

\section{c. Pendugaan Tingkat Pengusahaan}

Tingkat pengusahaan ini dapat diketahui dari nilai hasil perbandingan antara produksi aktual dengan potensi nilai total allowabel catch (TAC) sebagai acuannya. Menurut Pauli 1983, perhitungan tingkat pemanfaatan sebagai berikut [4] :

$T P_{f}=\frac{f i}{f J T B} \times 100 \%$

Keterangan :

TPf : Tingkat pengusahaan

$\mathrm{Fi} \quad$ : Rerata effort 5 tahun

\section{d. Pendugaan Potensi Cadangan Lestari}

Pendugaan potensi candangan lestari menggunakan Model Walter-Hilborn cara satu dan cara dua [1]. Persamaan dasar model WalterHilborn cara satu dan cara dua sebagai berikut [5]: 
1. Walter-Hilborn Cara Satu

$$
\frac{U_{(t+1)}}{U_{t}}-1=r-\left[\frac{r}{k+q}\right] U_{t}-q \times f_{t}
$$

2. Walter-Hilborn Cara Dua

$$
\left[U_{(t+1)}\right]=r \times U_{t}-\left[\frac{r}{k * q}\right] \times U_{t} 2-q \times U_{t} \times F_{t}
$$

\section{e. Pendugaan Cadangan Stok Tahun 2015}

Pendugaan biomass pada tahun 2015 menggunakan persamaan

$$
\begin{aligned}
B_{t+1} & =B_{t}+\left(r B_{t}-\left(\frac{r}{k}\right) B_{t^{2}}\right)-q f_{t} B_{t} \text { atau } \\
B_{t+1} & =B_{t}+P d_{t}-Y_{t} \\
P d_{t} & =r_{b t}-\left(\frac{r}{k}\right) B t^{2} \\
Y_{t} & =q \times f \times B_{t}
\end{aligned}
$$

Keterangan:

$$
\begin{array}{ll}
B_{t+1} & : \text { Stok biomas pada tahun } \mathrm{t}+1 \\
B_{t} & : \text { Stok biomas pada tahun } \mathrm{t} \\
Y_{t} & : \text { Hasil tangkapan pada tahun } \mathrm{t} \\
P d_{t} & : \text { Produksi biomas pada tahun } \mathrm{t} \\
r & : \text { Koefisien pertumbuhan } \\
k & : \text { Carying capacity } \\
q & : \text { Catchapability }
\end{array}
$$

\section{HASIL DAN PEMBAHASAN}

\section{Hasil Tangkapan Ikan Tuna}

Hasil tangkapan ikan tuna sirip kuning (Thunnus albacares) didapatkan dari data statistik perikanan tangkap Jawa Timur tahun 1990-2015 yang telah diolah (Gambar 1).

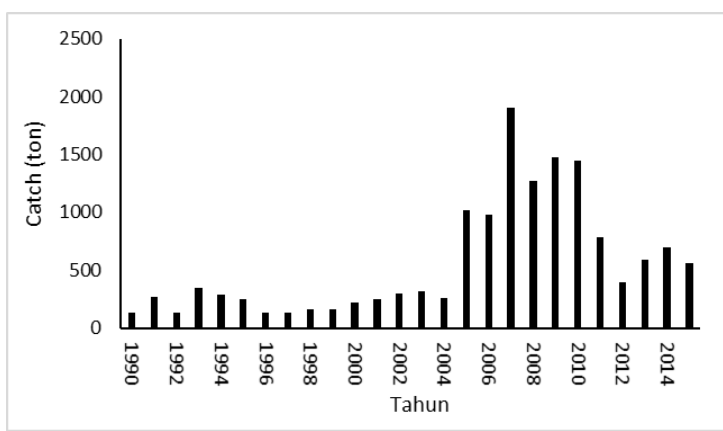

Gambar 1. Hasil tangkapan ikan tuna sirip kuning (Thunnus albacares)

\section{Standarisasi Upaya Penangkapan}

Standarisasi upaya penangkapan bertujuan untuk menyetarakan kemampuan keempat alat tangkap dengan acuan produktivitas ( $\mathrm{kg} /$ trip) alat tangkap. Diagram produktivitas alat tangkap dapat dilihat pada Gambar 2.

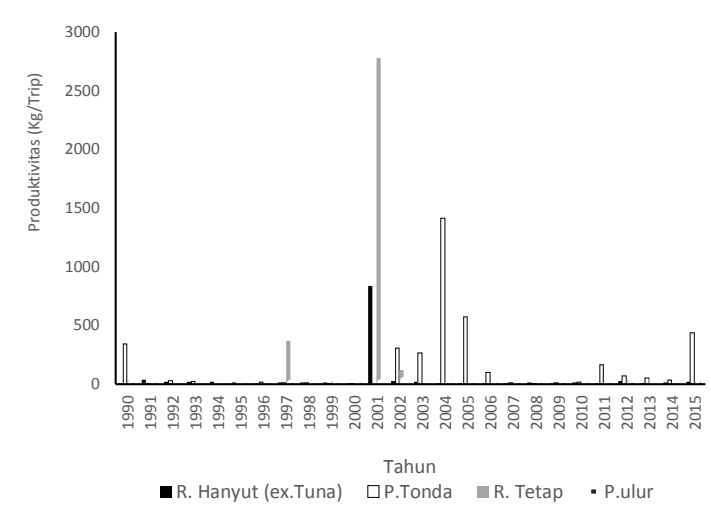

Gambar 2. Produktivitas alat tangkap

Hasil perhitungan nilai FPI didapatkan dari rerata produktivitas (kg/trip) keempat alat tangkap dengan menggunakan Persamaan 1.

Tabel 1. Hasil standarisasi upaya penangkapan

\begin{tabular}{lllll}
\hline & R. Hanyut & R. & P. & P. Ulur \\
Rerata & 43,68 & 145,3 & 148,89 & 15,16 \\
FPI & 0.293 & 0.976 & 1 & 0.102 \\
Rasio & 3 & 1 & 1 & 10 \\
\hline
\end{tabular}

Rasio alat tangkap menunjukkan satu kali trip alat tangkap pancing tonda setara dengan $3 \mathrm{kali}$ trip alat tangkap rawai hanyut (ex rawai tuna) atau 10 kali trip alat tangkap pancing ulur atau 1 kali trip alat tangkap rawai tetap (Tabel 1). Selanjutnya didapatkan upaya penangkapan ikan standart (Gambar 3).

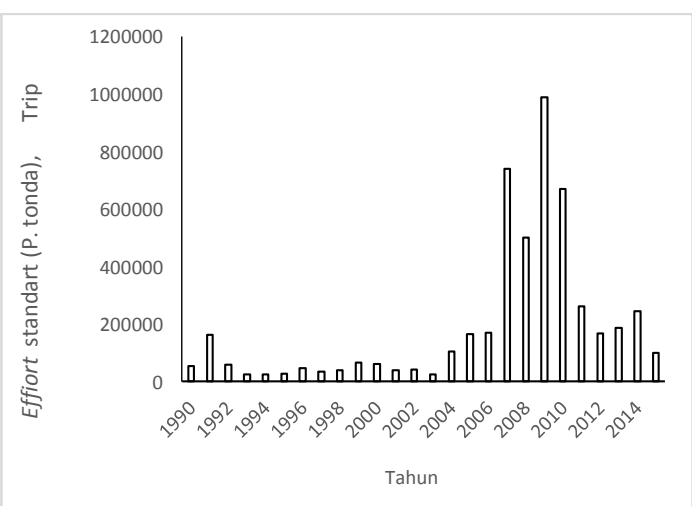

Gambar 3. Upaya penangkapan ikan standar Pendugaan Potensi Tangkap Lestari Model
Produksi Surplus

a. Model Equilibrium 
Analisis model Schaefer hubungan anatara CpUE dengan effort pada model Schaefer adalah linear negatif, sedangkan pada model Fox adalah exponensial negatif, sehingga pada saat analisa regresi linier tunggal diturunkan menggunakan fungsi $l n$

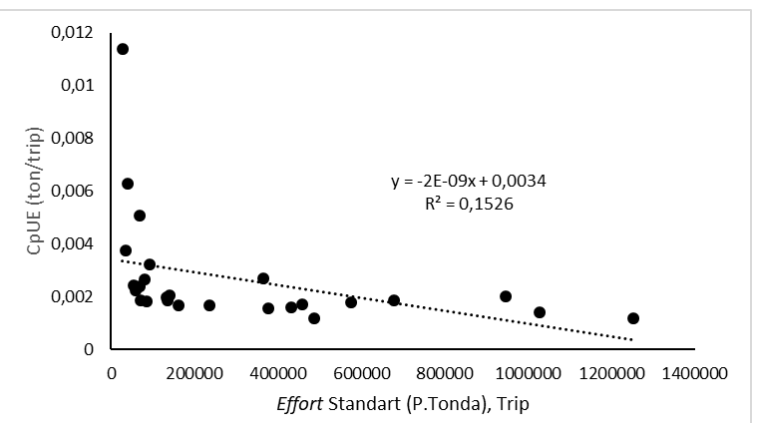

Gambar 4. Hubungan CpUE dengan effort model Schaefer

Berdasarkan analisis hubungan CpUE dengan effort pada model Schaefer CpUE = 0,00000000098f+ 0,003418398 (Gambar 4). Pada model Fox persamaan hubungan CpUE dengan effort adalah $\mathrm{CpUE}=-5,84456 \mathrm{e}^{(-0,00000081 \mathrm{f}}$ (Gambar 5).

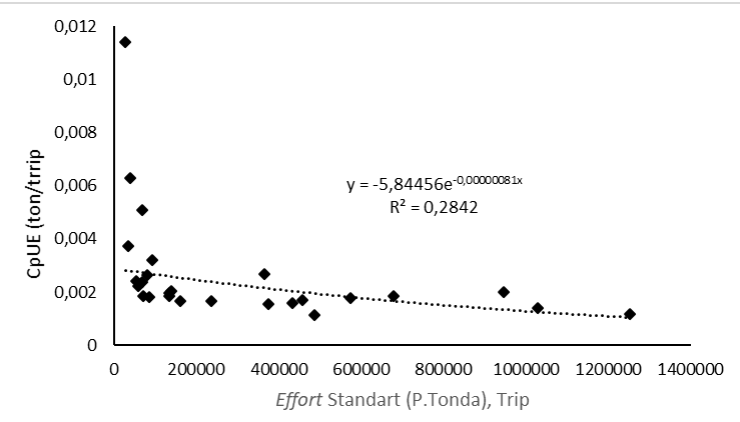

Gambar 5. Hubungan CpUE dengan effort model Fox

Dari hasil persamaan model Schaefer dan Fox kemudian dilakukan analisis dalam menduga nilai estimasi hasil tangkapan, MSY dan JTB. Berikut hubungan hasil tangkapan dengan usaha (trip) disajikan dalam grafik pada Gambar 6 .

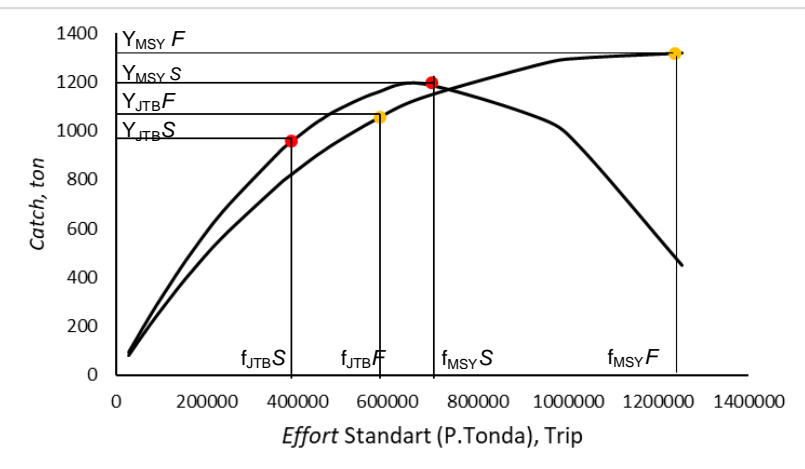

Gambar 6. Hubungan catch dengan effort model Schaefer dan Fox
Tabel 2. Hasil Analisis model Schaefer dan Fox

\begin{tabular}{|c|c|c|c|}
\hline Model & Schaefer & Fox & Satuan \\
\hline$R^{2}$ & $15 \%$ & $28 \%$ & - \\
\hline f.sig & $4,8 \%$ & $0,5 \%$ & - \\
\hline$f_{M S Y}$ & 699.547 & 1.236 .774 & Trip \\
\hline $\mathrm{Y}_{\mathrm{MSY}}$ & $1.195,665$ & 1317,453 & Ton \\
\hline$f_{\text {JTB }}$ & 386700 & 583.351 & Trip \\
\hline $\mathrm{Y}_{\mathrm{JTB}}$ & 956,532 & $1.053,963$ & Ton \\
\hline
\end{tabular}

Dapat dilihat dari Tabel 2, hasil analisis regresi didapatkan nilai $\mathrm{R}$ square pada model Schaefer dan model Fox memiliki nilai lebih tinggi dibandingkan nilai f.sig yang artinya hubungan antara variabel $(x)$ dan varibel $(y)$ signifikan. Penentuan model dalam menentukan status perikanan tuna sirip kuning (Thunnus albacares) dilihat dari nilai $\mathrm{R}$ square yang dihasilkan dari analisis regresi, pada model Fox memiliki nilai lebih tinggi dibandingkan dengan nilai R square pada model Schaefer $(28 \%>15 \%)$. Model Fox terpilih menjadi model terbaik berdasarkan keakuratan pada hasil parameter biologi, dengan pertimbangan meperhatikan nilai b negatif pada hasil analisis regresi, nilai $R$ square yang dihasilkan, serta tingkat signifikasi sehingga pada model Fox dianggap paling logis dalam menentukan status sumberdaya ikan tuna di perairan Samudra Hindia Jawa Timur [6].

\section{b. Analisis Non-Equilibrium Model}

Analisis non-equilibrium model dengan menggunakan model Walter-Hilborn didapatkan hasil sebagai berikut [1]:

Tabel. 3 Hasil analisis model Walter-Hilborn

\begin{tabular}{lrrr}
\hline & WH 1 & WH 2 & \multicolumn{1}{c}{ Satuan } \\
\hline $\mathrm{r}$ & 0,703127 & 0,6386287 & - \\
$\mathrm{b} 2$ & $-63,787$ & $-132,680$ & - \\
$\mathrm{q}$ & $-5,3 \times 10^{-7}$ & $5,1 \times 10^{-7}$ & - \\
$\mathrm{k}$ & $20.760,576$ & $9.407,36$ & Ton \\
$\mathrm{Be}$ & 10380.288 & 4703.68 & Ton \\
$\mathrm{R}^{2}$ & $15 \%$ & $53 \%$ & - \\
fsig. & $16 \%$ & $0.082 \%$ & \\
\hline
\end{tabular}

Berdasarkan Tabel 3, hasil dari model WalterHilborn cara 1 didapatkan nilai fsig. > $\mathrm{R}$ square $(16 \%>15 \%)$ yang artinya variabel $(x)$ tidak signifikan dalam mempengaruhi $(y)$, selain itu nilai $\mathrm{R}$ square pada model $\mathrm{WH}$ cara 2 memiliki 
nilai lebih tinggi $(53 \%>16 \%)$, oleh karena itu model WH 1 tidak tepat jika digunakan, sehingga digunakan model WH 2 dalam analisis nilai MSY, JTB serta menduga stok tahun 2015.

Nilai MSY pada non-equilibrium model didapatkan dari Persamaan 11 sehingga didapatkan nilai $\mathrm{Y}_{\mathrm{MSY}} 1501,953$ ton dan nilai $\mathrm{f}_{\mathrm{MSY}}$ dengan menggunakan Persamaan 12 kemudian dilanjutkan dengan Persamaan 13 didapatkan nilai $\mathrm{f}_{\text {MSY }}$ 1.330.369 trip. Nilai $\mathrm{Y}_{\text {JTB }}$ didapatkan dari $80 \%$ dari $\mathrm{Y}_{\mathrm{MSY}}$ (Persamaan 15) didapatkan nilai 1201,562 ton dan nilai $f_{J T B}$ didapatkan dari Persamaan 15 kemudian dilanjutkan ke Persamaan 16 didapatkan nilai $\mathrm{f}_{\text {Jтв }} 1.609 .457$ trip.

Nilai biomass ikan tuna saat kondisi JTB (Persamaan 15) sebesar 6807 ton. Hasil dari permodelan didapatkan biomass ikan tuna pada tahun 2015 didapatkan nilai 5.420,298 ton dengan nilai pemanfaatan biomass pada tahun 2015 sebesar 80\% dari nilai JTB (Gambar 7).

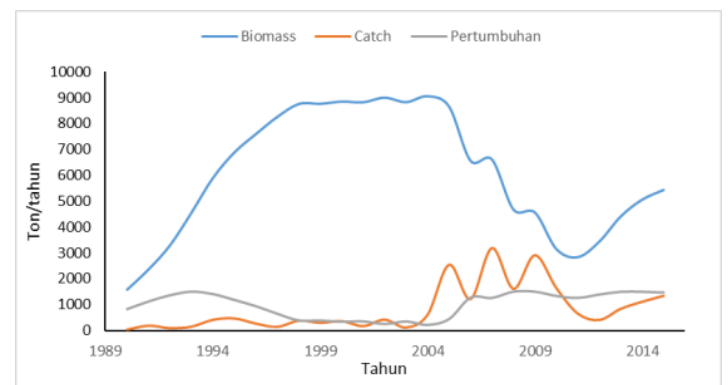

Gambar 7. Dinamika Stok Tuna Sirip Kuning (Thunnus albacares) di perairan selatan Jawa Timur tahun 1990-2015.

\section{Status Sumberdaya Ikan Tuna Sirip Kuning (Thunnus albacares)}

Penentuan dasar dalam menduga status sumberdaya ikan tuna sirip kuning diperairan selatan Jawa Timur dengan model equilibrium menggunakan model Fox didapatkan tingkat pengusahaan pada saat JTB $107 \%$ atau berlebih $7 \%$ dari nilai $\mathrm{f}_{\text {गтв }}$ dengan status pengusahaan over exploited posisi perikanan tuna 10 tahun terakhir yang diaplikasikan dalam model fox pada Gambar 8.

Sedangkan pada model non-equilibirum didapatkan nilai sisa biomass ikan tuna pada tahun 2015 didapatkan sisa biomass sebesar 80\% dengan biomass pada saat JTB dengan status biomass over exploited (Gambar 9). Status perikanan tuna di Samudura Hindia kondisi tangkap madidihang pada 2016 mencapai 35.838 ton (Indonesia) dan 412.679-ton (keseluruhan) pada status overfished and subject to overfishing, sementara jenis albakora dan tuna mata besar dalam kategori not overfished and subject to overfishing dengan total tangkapan di Indonesia masing-masing adalah 7.300 ton dan 86.586 ton [7].

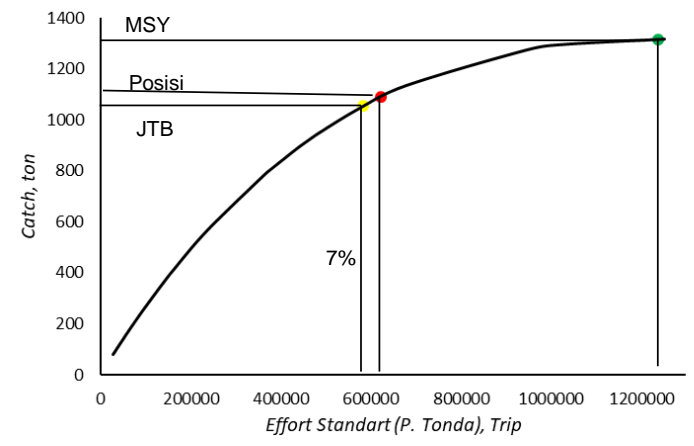

Gambar 8. Posisi perikanan tuna 10 tahun terakhir dalam model Fox 1970

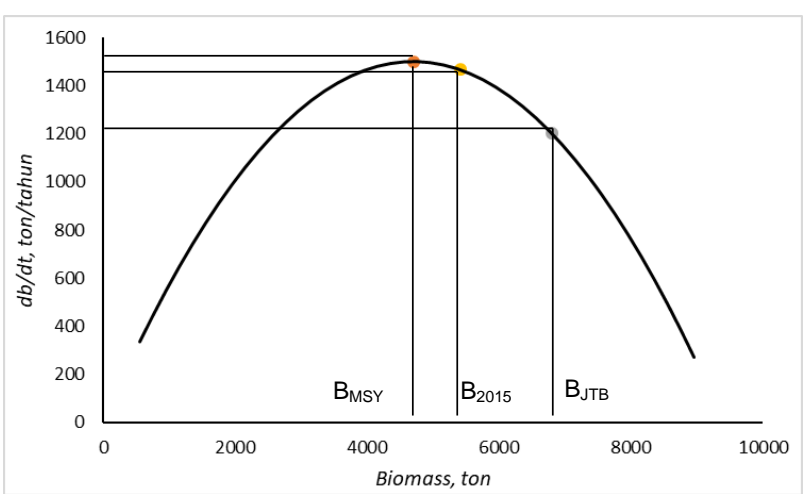

Gambar 9. Posisi biomass tuna tahun 2015

\section{Alternatif Pengelolaan Sumberdaya Ikan Tuna Sirip Kuning (Thunnus albacares)}

Pengelolaan sumberdaya ikan tuna sirip kuning diperairan selatan Jawa Timur dengan mengestimasikan upaya penangkapan ikan diturunkan sebesar 5\% dari upaya penangkapan tahun 2015 sebesar 461.716 trip dengan rincian 300.116 trip pada saat musim tenggara dan 161.600 trip pada saat musim barat sehingga akan didapatkan biomass sebesar 5923,227 ton atau setara dengan $87 \%$ dari biomass pada saat JTB (Gambar10).

Alternatif yang ditawarkan akan menghasilkan kenaikan biomass sebesar 9\% dibandingkan biomass pada tahun 2015 dan hasil tangkapan naik sebesar 4\% dibandingkan tahun 2015. Beberapa langkah kebijakan telah diatur dalam konferensi intrernasional salah satunya berdasarkan resolusi IOTC 17/01 pada spesies madidihang untuk menurunkan tangkapan minimal $10 \%$ dari total tangkapan Indonesia di tahun 2014[4], dimana saat ini Indonesia telah berhasil mengimplementasikan resolusi tersebut [8] 


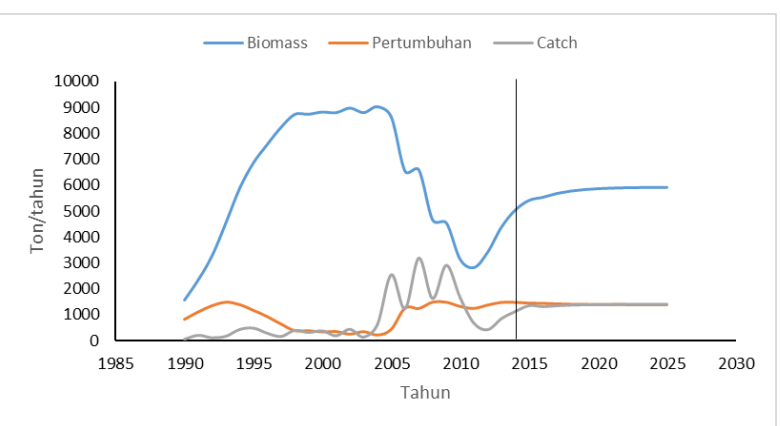

Gambar 10. Hasil manajemen upaya penangkapan

\section{KESIMPULAN DAN SARAN}

\section{Kesimpulan}

1. Nilai Maximum Sustainabel Yield (MSY) menggunakan model Fox (1970) didapatkan nilai $\mathrm{Y}_{\mathrm{MSY}} 1317,453$ ton, $\mathrm{f}_{\mathrm{MSY}}$ sebesar 1.236.774 trip. Nilai JTB didapatkan $\mathrm{f}_{\mathrm{JTB}}$ dengan nilai 386.700 trip dan У $т в 1.053,963$ ton.

2. Status pengusahaan ikan tuna sirip kuning (Thunnus albacares) di perairan Selatan Jawa Timur dengan acuan nilai $f_{\text {Jтв }}$ yang diperoleh dari model fox 1970, didapatkan tingkat pengusahaan sebesar $107 \%$ sehingga didapatkan status pengusahaan over exploited. Sisa biomass ikan tuna pada tahun 2015 sebesar 5420, 298 ton atau setara dengan $80 \%$ dari nilai biomass pada saat JTB didapatkan status over exploited.

3. Alternatif pengelolaan sumberdaya ikan tuna sirip kuning (Thunnus albacares) di perairan Selatan Jawa Timur adalah dengan upaya penangkapan ikan diturunkan sebesar 5\% dari upaya penangkapan tahun 2015 sebesar 461.716 trip dengan rincian 300.116 trip pada saat musim tenggara dan 161.600 trip pada saat musim barat sehingga akan didapatkan biomass sebesar 5923,227 ton atau setara dengan $87 \%$ dari biomass pada saat JTB

\section{Saran}

a. Saran untuk penelitian

1. Diharapkan adanya penelitian lebih lanjut untuk mengetahui aspek dinamika populasi ikan tuna sirip kunig (Thunnus albacares)

2. Diharapkan adanya penelitian tentang pemetaan area penangkapan ikan tuna untuk manajemen perikanan tuna lebih baik

b. Saran untuk pemerintah

1. Diharapkan adanya manajemen pengelolaan sumberdaya ikan tuna (Thunnus spp.) untuk memulihkan kembali sumberdaya ikan tuna dikarenakan status pengusahaan dan pemanfaatan biomas ikan tuna yang over exploited.

2. Diharapkan adanya pengelolaan peletakan alat bantu

\section{DAFTAR PUSTAKA}

[1] Hilborn, R., \& Carl J. Walter. 1992. Quantitative Fisheries Stock Assessment: Choice, Dynamics \& Uncertainty. Routledge, Chapman \& Hall, Inc.

[2] Badrudin, Aisyah, dan Ernawati,T. 2004. Penelitian Ikan Demersal di Sub Area Laut Jawa. Departemen Kelautan dan Perikanan. Jakarta.

[3] Sparre, P dan Venema, S.C. 1999. Introduksi Pengkajian Stok Ikan Tropis. Buku 1: Manual Pusat Penelitian Dan Pengembangan Perikanan: Badan Penelitian Dan Pengembangan Pertanian. Jakarta.

[4] Lubis, R.S., Mulya, M.B., Desrita. 2013. Potensi, Tingkat Pemanfaatan dan Berkelanjutan Ikan Tembang (Sardinella spp.) Di Perairan Selat Malaka, Kabupaten Serdang Bedagai, Sumatra Utara. Universitas Sumatra Utara.

[5] Setyohadi, D. 2009. Studi Potensi Dan Dinamika Stok Ikan Lemuru (Sardinella Lemuru) Di Selat Bali Serta Alternatif Penangkapannya. Perikanan (J. Fish. Sci.) 11(1): $78-86$

[6] Mulyani, AT. 2013. Kebijakan Pengembangan Ekonomi Perikanan Tangkap Berkelanjutan di Provinsi DKI Jakarta. Sekolah Pascasarjana. Institut Pertanian Bogor. Bogor.

[7] Loka Riset Perikanan Tuna, 2017. National Report Status Perikanan Tuna Samudera Hindia tahun 2017. Tidak Diterbitkan.

[8] Loka Penelitian Perikanan Tuna, 2014. Laporan Riset Genetik dan Biologi Perikanan Tuna. 74 hal 